\title{
Dreaming during COVID-19: the effects of a world trauma
}

\author{
Cristina Marogna, Emanuele Montanari, Silvio Contiero, Klodjana Lleshi \\ Department of Philosophy, Sociology, Education \& Applied Psychology (FISPPA), University of Padua, Italy
}

\begin{abstract}
On March 11, 2020, the World Health Organization (WHO) declared a state of health emergency affecting the entire world population. Given the serious practical and psychological difficulties and complications that have been experienced during this period, many scholars have created hypothesis, as a consequence, an increased possibility of developing post-traumatic stress disorder (PTSD) within the general population with significant implications for one's dream activity. Participants in the study were recruited via the instant messaging application 'WhatsApp' for a period of 14 days. The study consisted of three phases: the first phase provided information on the purpose of the research and how to carry it out; in the second phase, each participant, using the Bionian model of dream experience as a focus, was asked to write down dreams, emotions and free connections/associations related to the dream. At the end of the collection, the texts obtained were analysed by means of a qualitative analysis performed with the aid of the MAXQDA software. The study confirms the computational and exploratory analysis of the text carried out in the research of Pesonen et al. (2020), finding also in our sample the presence of the hypothesized clusters going to explain the manifestation of imagery related to COVID-19 also within the dream activity. To confirm this, the nightmare of participant number 6 of the study is reported. The following qualitative research has offered an insight into the traumatic nature of the COVID-19 pandemic, showing how many unmetabolized 'daytime elements' have been reproposed in the dream scenario, recalling the symptomatology of PTSD through the presence of distressing content that affect the quality of sleep and the daily life of the individual.
\end{abstract}

Correspondence: Cristina Marogna, Department of Philosophy, Sociology, Education \& Applied Psychology (FISPPA), University of Padua, Via Venezia 14, 35131 Padua, Italy.

Tel.: +39.0498276652.

E-mail: cristina.marogna@unipd.it

Acknowledgements: we would like to show our gratitude to the dreamers for sharing their precious nightmares with us, allowing our study to be conducted.

Contributions: CM, EM, SC, KL, contributed to the design and implementation of the research, to the analysis of the results and to the writing of the manuscript in equal contribution.

Conflicts of interests: the authors declare no potential conflict of interests to disclose.

Ethical standards: the authors affirm that all procedures contributing to this work conform to the ethical standards of the national and institutional committee responsible for human experimentation with the 1975 Declaration of Helsinki, as revised in 2008. The authors state that ethical approval for publication of this paper was not required by their local ethics committee.

Citation: Marogna, C., Montanari, E., Contiero, S., \& Lleshi, K. (2021). Dreaming during COVID-19: the effects of a world trauma. Research in Psychotherapy: Psychopathology, Process and Outcome, 24(2), 188-199. doi: 10.4081/ripppo.2021.541

Received for publication: 15 March 2021.

Revision received: 29 July 2021.

Accepted for publication: 29 July 2021.

This work is licensed under a Creative Commons Attribution NonCommercial 4.0 License (CC BY-NC 4.0).

${ }^{\circ}$ Copyright: the Author(s), 2021

Licensee PAGEPress, Italy

Research in Psychotherapy:

Psychopathology, Process and Outcome 2021; 24:188-199

doi:10.4081/ripppo.2021.541
Key words: Dreams; nightmares; post-traumatic stress disorder; COVID-19.

\section{Introduction}

On 11 March 2020, the World Health Organization (WHO) declared that the virus that had been spreading for several months could be considered a global pandemic. The severe acute respiratory syndrome-related coronavirus 2 (SARS-CoV-2) is a respiratory infection, due to the contraction of the coronavirus disease 2019 (COVID-19). Many studies, in the last year and a half, have highlighted the central role of nightmares in people's dream experiences, both as a result of the stress produced by the pandemic situation we are living in, and as a potential exacerbator of underlying psychopathological manifestations, i.e. anxiety disorders or depressive symptoms. San Martin et al. (2020) recall how exposure to traumatic events can act as a precipitating factor for a state of hyperarousal, with the presence of a higher number of nightmares and more lucid and vivid dreams. The latter may result from a failure of adaptive mechanisms to respond to stressful situations. Since the onset of COVID19 limitations, numerous people have spontaneously reported to remember more vivid dreams, even going so far as to complain about recurring nightmares in various social platforms (Kilius et al., 2021).

Dreams and nightmares have an important function for the psyche; in fact, according to the threat simulation theory (TST), dream activity is conceptualized as a mechanism to 'train' oneself and learn new survival strategies 
within a protected environment such as one's dreams. The emotion regulation theory (ERT), on the other hand, argues that the function of dreams is to regulate emotions through psychological and neuronal mechanisms such as desomatting, leading to the resolution of emotional problems and the extinction of fearful memories. The social simulation theory (SST) considers dreams as a reminder of everyday life memories and a useful mechanism for training new strategies of social behaviour that can, again, be tested in a protected environment without any particular consequences (Mota et al., 2021). The Continuity Hypothesis holds that dreams are influenced by the worries and thoughts we have during daily life, thus being reflected in dream activity (Barrett, 2020). Many studies relating to these areas of research have been conducted in different parts of the world:

Italy (Dondi et al., 2021; Innocenti et al., 2020; Scarpelli et al., 2021), Spain (San Martin et al., 2020), China (Guo \& Shen, 2021), Brazil (Mota et al., 2021; Musse et al., 2020), USA (Schredl \& Bulkeley, 2020), Turkey (Akkus, Sahin, Kanbay \& Ünlü, 2021) and Canada (Solomonova et al., 2021; Kilius, Abbas, McKinnon \& Samson, 2021). The salient element that emerges is the importance given to the historical period that we are living through as a 'collective trauma' that reflects in one's life and dream space as a stressor, which in turn has consequences in the waking state, thus triggering a vicious circle that increases stress and weakens people's psychic defences.

An important issue concerns gender differences: there are in fact several studies indicating that women had a higher frequency of nightmares during the pandemic period (Barrett, 2020; Musse et al, 2020; Scarpelli et al., 2021; Solomonova et al., 2021). Barrett (2020) tries to explain this gender difference by considering that women are up to three times underpaid compared to men and with greater job insecurity, that they are in most cases the "caregivers' at home (making them more vulnerable) and that almost $70 \%$ of the world's health workforce is female. Kilius et al. (2021) conducted a study of a sample of 70 Canadian students, most of whom reported experiencing more post-pandemic nightmares $(42.2 \%)$; within this sample, the gender difference was found to be significant and in favour of women.

In a study conducted by Solomonova et al. (2021) the most common dream theme that was found was 'trying to do something over and over again' $(51.55 \%)$, which surpassed 'being chased' (29.24\%) and 'students, professors, studying'. A new theme that was recorded was 'being separated from your loved ones' (29.65\%). Themes related to the pandemic were not as high as might be expected (7.64\% germs/contamination; $12 \%$ being in hospital; $14.8 \%$ being ill). The 7 major themes that were mostly represented in their sample were ineffectiveness $(62.40 \%)$, human threats $(42.46 \%)$, death $(38.95 \%)$, pandemic $(37.19 \%)$, paralysis $(27.79 \%)$, paranormal phe- nomena (26.24\%), natural threats (18.60\%). MacKay \& DeCicco (2020) conducted a study on a sample of 19 students at Trent University. The authors noted an increase in animal imagery, greater changes in location and more virus-related content. After further regression analysis they also found more food and head imagery. The authors here believe that the head and the food symbolise, respectively, the part of the body most affected by the virus (shortness of breath, coughing, temperature control) and the fact of having stocked up on food and not being able to leave the house.

\section{The role of dreams in emotional regulation}

Work on dreams has led researchers to increasingly recognise the role that sleep plays in the consolidation of emotional memories in each of us; research highlights the irrefutable role it plays in the health of our brain and its functioning. It has been hypothesised that one of the functions of dreaming is to process, interpret and reorganize the narrative of the material accumulated in memories during waking hours and to play an active role in the reorganization of affective information, contributing to the consolidation of emotional memory itself (Sterpenich, Perogamvros, Tononi, \& Schwartz, 2020). Dream activity is therefore characterized by internally generated emotional and sensorimotor experiences, which promote the reorganization of cortical networks aimed at psychological well-being (Messina et al., 2021). The activity is thus diverted from the motor systems and is then directed to the perceptual systems. A wide-ranging debate has been developed on this subject and there have been many theoretical models that have formalized these concepts, focusing on the function performed by dreams; among these is Revounso's (2000) theory of threat simulation (TST). Revounso formulated the hypothesis that dream activity would provide 'virtual proof' of threatening events, allowing simulations of events deemed threatening to promote conflict resolution itself, 'depleting' the negative charge of the experiences. The TST theory proposes that this can be done by involving neurocognitive mechanisms involved in the perception and avoidance of threats.

\section{REM or not REM is the dilemma?}

Scientific evidence using neuroimaging methodology has reported that the neural substrates that control emotions during the waking state are responsible for the processes involved in the regulation of REM sleep. Therefore, it is interesting to observe what these studies report; many of the afferent and efferent fibres of the two main cortical areas, which play a key role in the production of dreams, i.e. the temporo-parieto-occipital junction (TPJ) and the prefrontal-ventromedial cortex (vmPFC), emerge as being connected to the white matter and limbic system. Many studies indicate that the intensity of emotional involvements, experienced during waking hours can be in- 
corporated into dreams. A study conducted by Schredl in 2006 provides evidence for this notion. Participants in this study recorded their waking dreams and the type and intensity of emotions experienced during the day for a fortnight, and it was found that depending on the intensity of the emotions they felt during their day, these were incorporated into dream activity and influenced the wakingsleep continuity. Further aspects, which play a role in the wake-sleep continuity, emerge as the novelty of the experience that the individual experiences and the personal meaning that he or she attributes to the event; according to Payne and Nadel (2004) dreams intervene in the weaving and integration of new information with old material. This evidence supports the hypothesis that sleep and dreams play an active role in learning and memory consolidation; Sitckgold et al. (1995) conducted research using a methodology called 'Nightcap', and managed to differentiate between dreams occurring in the nonREM phase of sleep and those in the REM phase. The contents of the former involve everyday life events, which have less emotional resonance; dreams occurring in this phase are involved in stabilising memory. The emotional intensity and complexity recorded in the dreams that occur in the REM phase is very high; it is in this phase that dreams take on the task of integrating, comparing and reorganizing experiences by comparing them with those already stored (Stickgold, Pace-Schott \& Hobson, 1994). In this sleep phase, techniques such as functional neuroimaging record the activation of the amygdala and hippocampus, which play a primary role in the processing of long term emotional memory (Van der Helm \& Walker, 2012). Experimental research carried out by Kramer (2014) indicates that abnormalities in the sleep-wake rhythm, such as nightmares, can lead to an impairment of this process due to the failure of the REM mechanism to contain the high intensity of emotions experienced (Kramer, 2014); it is assumed that they occur in a person who is unable to 'discharge' their energy without the dream being interrupted, therefore leading to the awakening of the individual and a failure of the fear extinction system. Neuroscientific research, also involving non-clinical subjects, can elucidate physiological processes that have an emotional resonance and influence both sleep and dreams and in our case nightmares.

\section{Nightmares: virtual evidence of threatening events}

Sleep disorders are currently included in two major diagnostic manuals, the Diagnostic and Statistical Manual of Mental Disorders (DSM-5) and the International Classification of Sleep Disorders (ICSD3, 2014). In the International Classification of Sleep Disorders (ICSD), it has been reported that there are different ways in which dreams can affect and impair everyday life of individuals; these manifestations can cause emotional manifestations that are a source of high levels of distress. An interesting aspect was highlighted in a study conducted by Hobson et al. (2002); although the perceptual experiences in dreams are mainly visual, and although more than $50 \%$ are seen in colour rather than in black and white (Okada et al., 2005), the content of dreams is not limited to one sensory modality. Metzinger's (2003) studies found that, although rarely, other perceptual experiences such as perceiving pain, smelling and tasting can be experienced during a dream. In the case of sleep disorders, this can have negative implications and increase negative emotions that are experienced. The most common and widespread form of disturbed dreaming is nightmares, defined as 'recurrent, highly dysphoric dreams characterized by vivid and detailed images involving threats to survival, safety or physical integrity'. In the ICSD-3 nightmares are placed in the category of parasomnias.

Parasomnias are thought to be due to abnormal activation of physiological systems characterized by the presence of undesirable behavioural and vegetative phenomena. Depending on the phase of sleep in which they emerge, these can be distinguished into non-REM phase parasomnias and REM phase parasomnias. Nightmares fall within the latter. Scientific research over the last half century, although not having arrived at a standard definition of nightmares, has gradually made it possible to distinguish between two classes of nightmares (Nielsen, \& Zadra, 2005): i) idiopathic nightmares: imaginary events, not necessarily related to a traumatic event; ii) post-traumatic nightmares: imaginary events characterized by replicas of the traumatic event, containing emotions and content symbolically associated with the trauma.

Nielsen and Levin (2009) supported the hypothesis that dreams play an active role in fear extinction. They hypothesised that nightmares may be "the consequence of a dysfunction in a network of processes that, during regular sleep, have the adaptive task of cancelling the memory of fearful events' (Nielsen \& Levin, 2009, p. 667).

The emotional components typically associated with nightmares are fear, anxiety or terror, but the presence of dysphoric emotions such as anger, sadness and disgust has also been documented; they are therefore associated with high emotional distress (Zadra, Pilon, \& Donderi, 2006). Nightmares experienced by the dreamer are vivid and involve scenarios perceived as threatening. Discomfort, which stems from the emotional responses manifested in the nightmares, plays an integral part in clinical practice to identify the traumatic precursors (Zadra, \& Donderi, 2000). The model proposed by Nielsen and Levin supports the hypothesis that nightmares may be related to an interruption in the brain networks of the limbic, paralimbic and prefrontal regions, which are considered to be the core control of processes such as perception and representation of emotional stimuli, their expression and their regularization. The four regions identified by the researchers have been defined with the acronym 'AMPHAC' and involve the amygdala, the medial prefrontal cortex, the hippocampal complex and the anterior cingu- 
late cortex. As a result of their studies, it has been observed that impairment of these brain areas is present in individuals with sleep disorders and associated disorders such as post-traumatic stress disorder (PTSD) (Nielsen, \& Levin, 2009).

\section{Trauma: if you can dream it, you can deal with it}

Psychological trauma resulting from exposure to external events perceived as potentially dangerous to one's own life and that of others can lead to severe functional impairment. The traumatic experience, accompanied by horror, fear and a sense of helplessness can lead to the development of PTSD in which the associated hyperarousal is mainly due to the dysregulation of fear responses, with excessive release of noradrenaline and glucocorticoids. These alterations in the structure and biochemistry of brain networks have long-term effects, well beyond the traumatic event and its resolution, as a physical neuronal trace of the damage that has been suffered (Frewen, \& Lanius, 2006). PTSD is a psychopathological picture resulting from an external traumatic event, deriving from multiple factors, both personal and environmental. A characteristic symptom of the disorder is the experience of frightening and distressing intrusive experiences that haunt victims both during waking hours, with flashbacks and intrusive memories, and at night with nightmares. Nightmares and sleep disturbances are, in fact, strongly correlated with PTSD. The presence of recurrent nightmares is one of the criteria considered for the diagnosis of the disorder. Nightmares and PTSD symptoms are associated with impaired activity in the brain regions identified in Levin's AMPHAC model (2007). The regions whose activity is altered are the amygdala, the extension of the medial cortex (which has the fundamental task of regulating the emotional activity of the amygdala, favouring the production of new memories aimed at the extinction of fear), the hippocampus (which regulates extinction and the possibility of creating new ways of re-expressing the traumatic event) and the anterior cingulate cortex (which regulates the level of emotional expression and discomfort perceived bringing back the memory of the traumatic event). This alteration seems to be correlated with an increasing intensity of the frequency of nightmares and with specific characteristics of the disorder itself, such as the lack of emotional control, the bizarre characteristics of the dream and the reproduction of traumatic memories (Lieven \& Nielsen 2007; 2009; Stickgold \& Walker, 2009).

While each of these four regions have specific functions in emotional regulation, they operate in a coordinated fashion. According to researchers, the AMPHAC neural network is an integral part of the physiological infrastructure of normal dreaming; they also believe it plays an important role in shaping emotional images, both during normal and disturbed dreams (Levin \& Nielsen, 2007). A predominant hypothesis considers an increase in amygdala and hippocampal activity during nightmares and the possibility of an increase/reduction in the activity of medial and anterior cingulate cortex extension. Impaired activation of these brain areas is positively correlated with a pronounced and severe PTSD picture.

The amygdala, however, not only plays a primary role in fear conditioning but it also has a role in the modulation of emotional memory itself; it is responsible for the degree to which pseudo-receptive elements of dreams will be remembered and imprinted in the emotional memory of the dreamer. Stickgold (2005) speculates that this may be the reason why nightmares are so frequent. Consistent with Revounso's model, the dream should have the function of responding adaptively and regularizing the concerns that afflict the dreamer but in PTSD there is the depiction of traumatic memories of conditioned fear, and this makes its work more complex.

In a study conducted with patients suffering from Post Stress Disorder, Mellman et al. (2001) highlight the importance of working on the way in which traumatic memories are activated causing the interruption of the REM sleep state from which the individual wakes up.

\section{Dreaming on pandemic}

In several studies, the relationship between traumatic events previously experienced by an individual and the replication of the same in post-traumatic nightmares has been demonstrated (Miller et al., 2017). As a traumatic event, the pandemic and the lockdown that followed had the potential for the genesis or repetition of traumatic experiences. From the above studies it can be inferred that a traumatic experience such as the pandemic may have greatly affected the quality of sleep and the production of nightmares in the population, even more so given the repetition of trauma due to the new waves resulting in several periods of recrudescence and lockdown over the course of a year. The possibility of studying the nightmare in a non-clinical sample, using it as a metaphor for the trauma that has been suffered (Kohut, 1977) by identifying possible processing strategies in it, may be the way to foster greater resilience to confront uncontrollable events such as the pandemic afterwards, inside the clinical setting. Furthermore, the identification of recurring themes and images in the dreams of both the clinical and the non-clinical population can offer a valuable contribution to structure specific psychotherapeutic intervention that target healthcare's personnel, who has been carrying a heavy emotional load during the pandemic (Shatri et al., 2021; Presti et al., 2020; Caccamo et al., 2017).

In the last year and a half, numerous studies have been conducted which have confirmed this hypothesis and have made substantial contributions to the literature available to date. Gupta (2020) highlights the 're-emergence' of COVID-19-associated sleep symptoms in PTSD patients in remission; although none of the 20 patients included in this study reported contracting COVID-19, 55\% reported 
difficulty falling asleep, 70\% noted more fragmented sleep recently (with some waking up with disturbing dreams) and $80 \%$ reported nightmares. None of the patients described COVID-19-related themes. Although the themes were not directly related to the current pandemic picture, they were reenactments of past traumas that occurred during periods of change and stress (Gupta, 2020). Gupta argues that the 're-emergence' of traumatic dreams and nightmares in PTSD patients in remission may be useful in the primary and secondary prevention of PTSD itself. In Italy, several studies have been concerned with finding correlations between the typical symptoms of PTSD and the general feeling of stress brought about by the global pandemic, linked above all to aspects such as social isolation, quarantine and the greater attention demanded of everyone during the day. Casagrande et al. (2020) found that $7.6 \%$ of their reference sample (173 out of 2291) had a high score on the COVID19-PTSD, a modified version of the PTSD Checklist for the DSM-5; Gorgoni et al. (2021) found 63. Gorgoni et al. (2021) found a percentage of 63.8\% (691 out of 1091) of subjects who had a PSQI-A score $>3$, which indicates nighttime symptoms related to PTSD such as nightmares, flashing, feeling nervous, intrusive thoughts about the trauma, and acting out episodes in sleep. Lin et al. (2021) carried out a study on 528 Chinese health personnel sent to Wuhan in Fujian province; 144 (27.3\%) were assessed as having frequent nightmares. They reported higher scores for degree of worry about infection, worse mental health and shorter sleep duration during the night. Almost every PSQI score that was administered was higher in this group. Giardino et al. (2020), on the other hand, studied a sample of Argentinean healthcare workers $(n=1059)$ in which they found a $58.9 \%$ proportion of subjects reported nightmares or violent dreams, which are key symptoms of PTSD symptomatology and thus indicate a high risk of development. To these are added $70 \%$ positive responses regarding anxiety symptomatology and $81 \%$ regarding depressive symptomatology. Guo \& Shen (2021) conducted a study aimed at finding a correlation between continuous exposure to media reporting on the COVID-19 pandemic and certain anxietyrelated symptoms and the frequency of distressing dreams. This hypothesis was confirmed in a sample of 338 individuals. The theory put forward by Guo \& Shen (2021) is that media exposure can be traumatic and act as an unconditioned stimulus leading to an unconditioned response, such as anxiety and fear. This is reinforced by the fact that distress and scary dreams are positively correlated. The theory proposed by the authors thus concerns a possible development of PTSD from an indirect exposure, which then turns into distress and then rumination, as if one had actually been part of a traumatic experience.

\section{Aims of our research}

The analysis of the current available literature shows how the study of phenomena present in the nonclinical population is a valuable aid to understand what happens between therapist and patient in the psychotherapeutic setting (Abdel-Khalek, 2017; Bulkeley, \& Kahan, 2008; Scott, Harb, Brownlow, Greene, Gur \& Ross, 2017). In this sense, our research aimed to investigate dreams and nightmares present in a non-clinical sample in order to highlight some characteristics of PTSD due to the pandemic and which find space for expression in the dream.

The dream phenomenon presents itself as an unconscious attempt to give form and voice to this feeling, showing split contents that may belong both to the dreamer and to the environment in which he lives. In fact, the latter can feed the defensive mechanism through denial, the disregard of facts that occurred and their transformation into a sort of taboo inside this context.

\section{Materials and Methods}

\section{Description of the research sample}

Dreams were collected from a sample of 17 individuals $(17 \mathrm{~N}), 9$ female and 8 males, with a mean age of 24.94 and $\mathrm{SD}=3.45$.

The research subjects were engaged in a dream collection for a duration of 14 days (from $27^{\text {th }}$ April 2020 to $10^{\text {th }}$ May 2020). The collection carried out corresponds with the last week of phase 1 (Italian lockdown) and the first week of phase 2 .

\section{Data collection}

Given the limitations of the COVID-19 pandemic, participants were recruited via the end-to-end encrypted instant messaging application Whatsapp. The first stage involved sending informed consent, and then an audio message was sent to each participant explaining the purpose of the research and how it would be carried out and providing each participant with a practical example of what had been explained. During this time, the interviewees were asked to take notes and describe their dreams, specifying that the associations and emotions they felt should be noted down even if they could not remember the dreams. The annotated texts were collected through: voice notes, messages, calls and video calls.

At the end of the two weeks, a voicemail message was sent to explain the last part of the research, i.e. a request to share considerations about the experience, including critical points, strengths, observations and reflections about the experiences experienced while participating in the research.

In order to divide the material that was collected on a daily basis for each individual participant, it was divided into seventeen numbered folders; inside each folder there were other 15 folders plus a final summary.

After the collection of the material, the audios were uncoiled and the texts merged, creating a Word file for each subject, that was then divided into daily paragraphs containing all the exchanges and narratives that were made. 


\section{Tool}

The research mode deemed most appropriate for this collection was qualitative, both in terms of the type of material collected and the quantity of participants. Following the model offered by the work of Pesonen et al. (2020), MAXQDA 2020 software was used (Verbi Software, 2019).

MAXQDA is part of the group of computer programmes aimed at text analysis of qualitative data; in fact, the digitization of documents and other qualitative material has its origins in the 1960s with the use of computers in this field called CAQDAS, or Computer Assisted Qualitative Data Analysis Software.

Currently, this programme is used in various fields, such as psychology, sociology, anthropology, educational sciences and many others, providing an aid for the systematization of data, without providing additional interpretations or symbols. In fact, the latter is the task of the researcher who, after having collected and coded the data that are the basis of his research, has to make his own considerations and observations regarding the subject matter.

Therefore, in order to make an adequate use of this instrument, the researcher must set clear and defined hypotheses and research areas, thus continuing with modifications and re-elaborations in itinere, which however start from a precise basis.

The collected material was loaded onto the software and subjected to text analysis, using the key families concerning the topic of coronavirus identified in the study by Pesonen and colleagues (2020) as a model, for these were mostly in agreement with the characteristics and objectives of our research.

Three subdivisions of clusters emerge in the research carried out by Pesonen and colleagues (2020): the first refers to a general overview, where 11 'pandemic-specific' clusters appear among the 33 identified; in the second, the dream contents were collected and associated with each other, just considering the material provided by people who reported having experienced an increase in stress levels during the lockdown period; in the third, the clusters were generated by people who reported not noticing or slightly noticing an increase in stress levels.

Taking the research material of Pesonen et al. (2020) as a reference, the clusters investigated in this research are presented in Table 1.

As theoretical support for the analysis of all the material produced, we referred to Bion's theoretical model (1980, 1992, 1994), which considers everything that is narrated and shared by human beings as free association, about a dream, are a dream material. Bion considers dreaming as a broader process than the phenomenon that occurs during the night, that is, as a transformative capacity that can also be applied during the day: recounting a dream is equivalent to 're-dreaming' it. In this dynamic, the thoughts and stories associated with it become a dream experience that helps the individual to develop his unconscious and his $\alpha$ function; this process allows the significance of emotions, feelings and experiences ( $\beta$ elements) that would otherwise not be expressed. Supported by this theoretical model, we have also considered dream contents, the associations and reflections that our dream narrators made when telling of their dreams.

\section{Results}

After all the text strings were initialled and coded, following the groupings made (see Table 1), we observed a detection of all types of clusters and sub-clusters in different percentages (Table 2).

The number of codes found within the 17 documents were 274 and concerned all of the 'pandemic spe-

Table 1. Grouping of reference codes.

\section{Cluster}

Travel difficulties, overcrowding + Obstacles in returning home

Disregard of distancing

Surgery and problems

Surgery and troubles

Quarantine and disease symptoms + Patient care, cough

Apocalypse + Dystopia + Chase-escape in war and borders

Touching, being touched, physical contact

Touch

Elderly in trouble

Event cancellation

Home-school

Coronavirus contagion

Lockdown + Isolation anxiety + Crowd-restriction + Personal protective equipment 
cific' (Pesonen et al., 2020) labels made explicit in the Finnish study.

Looking at the various clusters grouped and coded together, the eleventh cluster has the highest percentage, namely 'Lockdown (15.0\%) + Isolation anxiety $(8.0 \%)+$ Restrictions for groups of people, crowds, gatherings $(10.9 \%)+$ PEP, Personal Protective Equipment (8.7\%)'. (42.6\%).

It is the largest one and, in order, it includes excerpts of text such as the following: 'The beginning was not easy, being locked in the house wasn't simple, especially in a small house where we are all together'; 'then this quarantine went on even longer and so there was a bit of anxiety... an awakening to say: 'Oh enough I can't take it anymore' and needing a bit of contact with the world and ... a bit psychopathic like ahahahah, like in need of hospitalization'; 'And we go to the cooperative, the shop, the supermarket. Where you can only get in a few at a time because of COVID'; 'And there we found another friend of ours who was looking for a mask. She explained to us that this distributor had been modified so there was no more junk food as usual, but it was giving out masks'.

This set of clusters is very explicit and recalls elements of everyday life in the period in which the collection was made, in fact the 'daytime residues', objects and situations do not have any particular hidden meanings to be unmasked but present the dreamers with contents related to everyday reality.

The second set of clusters according to the percentages is 'Apocalypse (1.1\%) + Dystopia (1.5\%) + Pursuits and escapes in war situations and the like (10.6\%)'. (13.2\%) and includes catastrophic or tense situations such as the following: 'Everyone was preparing, looking forward to $i t$, the moment this danger would arrive, precisely... people often went crazy. Well, they thought it was the end'; 'instead of... helping us to get out of this phase, in reality the operators were continuously... giving us the virus. For example, I went there to do the third swab, in reality they gave me a puncture and you don't do that. You take my blood and check that I'm healthy. But no, they gave me a shot, so they gave me more of the virus. Inside my head I continued thinking that they kept giving it to us for political reasons, social reasons, I don't know'; 'Whereas last time there were many of us, but nobody could put out the fire and we all ran away'.

In this set we can find the substantial presence of actions related to being chased and escapes of and from physical, intangible, unknown or known enemies, but generally threats that had to be captured and 'dealt with' or from which it was best to get as far away as possible.

As far as apocalyptic and dystopian contents are concerned, it is interesting to note that one of the few extracts is in line with some conspiracy views of the moment.

The third most present group in the collected texts is 'Difficulties in moving and gathering (10.9\%) + Obstacles in returning home (2.1\%)' $(13.0 \%)$, with expressions such as: 'I'm at the supermarket, it's full of people and everyone is queuing at the checkout'. They all have full trolleys. I have mine too and I try to get out of the way to find a place but I struggle and at a certain point instead of queuing at the checkout I make a mistake and they tell me that I am taking the entrance backwards'; 'But I went out almost immediately and took my bike home. I found myself in a sort of race through the main street of **** but I was scared because the bike had difficulty braking. I was constantly on the verge of running into trucks/machines in front of me.'

Here it is possible to notice how difficult it is to leave home, to try to return there or to go anywhere. Moreover, within this large cluster, expressions have also been coded that highlight how crowded certain dream places are, such as this one: 'When the children started to be a bit too many they started to go home'.

Table 2. Grouping of reference codes with percentages of presence identified in our sample.

\begin{tabular}{lc}
\hline Cluster & Percentage on pandemic-specific cluster of our sample \\
\hline Travel difficulties, overcrowding + Obstacles in returning home & $13.0 \%$ \\
\hline Disregard of distancing & $2.6 \%$ \\
\hline Surgery and problems & $1.1 \%$ \\
\hline Surgery and troubles & $5.5 \%$ \\
\hline Quarantine and disease symptoms + Patient care, cough & $13.2 \%$ \\
\hline Touching, being touched, physical contact & $7.7 \%$ \\
\hline Elderly in trouble & $1.1 \%$ \\
\hline Event cancellation & $1.5 \%$ \\
\hline Home-school & $4.0 \%$ \\
\hline Coronavirus contagion & $7.7 \%$ \\
\hline Lockdown + Isolation anxiety + Crowd-restriction + Personal protective equipment & $42.6 \%$ \\
\hline
\end{tabular}


So, there is a kind of fear of leaving a place that has become more like a prison, but at the same time it is the concretization of our last defence barrier (one's own home), thus risking both going against government directives and running the risk of running into problems or gatherings that could spread the virus.

In fourth place there are two clusters with equal shares: 'Coronavirus infection' (7.7\%) and 'Touching, being touched, physical contact' (7.7\%).

The first one refers to situations in which the participants talk about COVID-19, about who is positive, but above all about the fear of being infected and of infecting others as for example: 'I put my hands in my mouth and then I say 'No, I mustn 't, because I could catch a disease'. So, well, obviously, I would link this last part with this situation in which we have to wash our hands and so on, this anxiety. The infestation continues'.

The second cluster groups together pieces of text in which there are manifestations of physical contact and touch, such as hugs, kisses, handshakes, but also more traumatic ones such as punctures or finding someone rummaging through one's belongings, as it can be seen here: 'a man rummages in my bag and so he has stolen something from me'. In short, we can find an ambivalent feeling towards this human experience, which includes both the desire to return to live with the beloved ones, but this can at the same time be frightening, painful or intrusive.

At the fifth level we found the cluster of 'Quarantine and symptoms of illness $(2.6 \%)+$ Patient care, coughing $(2.9 \%)^{\prime}$. (5.5\%). It embraces both statements concerning quarantine, symptoms and care such as these: 'See, Giulia is here, she has been here in the hospital and had a complication, because ... it only seemed an allergy, instead it was ... anyway ... cold, so positive for coronavirus, she had some complications, she really risked death, because she had an internal haemorrhage' or 'Only one of them got hurt... a knee was skinned, all the blood was coming out. Then there was this girl, who I saw and I let her in, because she had morphine to give to the boys, to inject it in the vein, to relieve the pain, because otherwise he couldn't walk to take him to... where to treat him'.

With respect to the term 'quarantine', care was taken in labelling it, as many people used this word to refer to lockdown.

The sixth place is occupied by the cluster 'Didactics at a distance, school at home' $(4.0 \%)$ and it is hardly associated to particularly distressing contents, also because it emerges more as an associative element, while 'dreaming about' the day, and less frequently as part of a nocturnal oneiric phenomenon such as: 'I dreamt about the exam I have to take today, practically. Only, instead of being on Skype, because the exams are done by Skype, the exam was in the virtual classroom that we use for the lessons'.

The seventh position belongs to the label 'Disregard/disregard for keeping distance' (2.6\%), which was coded when the narrating person showed astonishment, punctuation, or incomprehension towards closeness behaviors that were discouraged at that time. An example is: 'I was at a class dinner and the next day the person sitting in front of me told me that we had hospitalized her brother for COVID that night'.

The penultimate place belongs to the cluster 'Event cancelled' $(1.5 \%)$ and among those taken into consideration it is possible to notice the schedule of going out, going to theatre shows, a birthday and deadlines such as the following: 'if I found out I was [positive], maybe there was also in the dream this matter I was saying, if I got sick now everything would screw up, right? The thesis, all that stuff'.

Finally, at the bottom of the list of clusters are two clusters with the same percentage: 'Surgery and problems' $(1.1 \%)$ and 'Seniors in difficulty'. (1.1\%).

The first was found in excerpts recalling the hospital environment, the problems related to it and in particular surgery. An example is: 'in the evening I saw a programme where they were doing surgery on people', while the other two recalled dreams about deaths in mortuaries and a person with serious health problems and a haemorrhage which had put her life in danger. Probably this cluster would have been more present in people who at that time were carrying out the medical profession or a health profession, but this is only a hypothesis.

The second one recalls what was widely communicated during the restrictions, i.e. the protection of elderly people who were most at risk by considering a prognosis in case they contracted the coronavirus or the situations in old people's homes. One segment of text is: 'an old woman had rung the bell and when I saw that she was soaked I let her in'.

The dreams collected and grouped in clusters can be described as 'daytime residues' of the current period; i.e. threats to be defeated or from which to flee as quickly as possible, contents reminiscent of conspiracy perspectives, ambivalent experiences with regard to one's own home, which is both the ultimate protection, but also an ivory cage, fear of infecting and being infected, emotions concerning physical contact which is desired, but is at the same time frightening because of the possibility of contagion or because of news about treatments carried out in hospital, compliance or not with the rules of social distancing and the use of PPE (personal protective equipment), daily experiences which become distant or frightening (e.g. concerts, public events, etc.) and concerns about the elderly population.

In the collection it was possible to observe how various elements of daytime life, which changed rapidly, involved a surplus of traumatic material to be 'digested' and metabolised.

A peculiarity of this research concerns subject 6 which reports a high density of codes ( 9.16 codes per thousand words), well represented by the following dream: 


\begin{abstract}
'the other dream instead, which lasted quite a long time... was... quite disturbing. I was inside a room, like a mortuary, where there were all dead people, some on tables, some up in cold rooms, like, and there was a man who, I don't know why... kept moving these dead people. So, he would take the sheet, I remember the detail that he folded it on the four sides, so he would take the four sides to move the dead and he would pull them down and, on that place, he would put another one... and that one maybe he would put in the cell. I mean, it was just a lot of turning around, so...these dead people. Yes, well, I woke up quite distressed and worried about it... another thing is that I had to clean up. So, I was turning my head so as not to see these dead people and I was trying to clean around, wash the floor around where all these tables were and... I'm thinking of a connection. A practical connection... more than anything else maybe speeches that came out these days, talking with a person that actually the only connection I make is not a practical one, like I have to do as you did in the example, but it is a connection with a person I talked to these days who.... his fatherin-law had died, he had seen... he told us that there were these areas of cells full of people waiting to be put there...

then I woke up and started thinking about all the things I had to do in reality this morning'.
\end{abstract}

The massive presence of distressing dream material related to the coronavirus in Subject 6 can be traced back to some traumatic events experienced personally: continuing to work in attendance despite the lockdown and the resulting concern for the health of family members, the death of a loved one due to the coronavirus, the hospitalization of acquaintances, and the concern for the end of the lockdown on 4 May. In the first week of dream collection, pandemic-specific clusters were the most present.

Another relevant element concerns the distribution of coronavirus-related clusters, i.e. 158 out of 274 belong to the collection carried out in the first week and thus at the most destabilizing moment of the pandemic experience.

\section{Discussion}

Dream activity and, in particular, nightmares that are present in a non-clinical sample can make one reflect about the intrapsychic suffering experienced during the pandemic and the "emotional toxins" that will remain, since it is linked to memory mechanisms as previously exposed. Many researches have testified that sleep difficulties are a distressing and frequently reported symptom following events considered traumatic (Cullen, Gulati, \& Kelly, 2020; Vindegaard, \& Benros, 2020). Our study, using a non-clinical sample, was able to highlight how effectively these aspects have infiltrated our unconscious by manifesting themselves in dream activity. The COVID-19 pandemic has brought the greatest global challenge of this generation; at this stage of action-oriented pandemic response it is particularly important to consider that this situation has placed the entire population in a condition of psychological vulnerability: children, adults, the elderly, workers and non-workers without distinction as is also evident from our study.

The study by Pesonen and colleagues not only focused on the variety of distressing dream contents present in 811 people, but also investigated the quality of sleep of 4275 individuals, revealing an increase in the number of hours dedicated to rest (54.2\%), but also of awakenings (28.6\%) and nightmares (26\%) compared to the period before the Finnish lockdown. With reference to the dream elements that emerged from the exploratory research, the total number of clusters is 33 , of which 20 have distressing characteristics and more than half $(55 \%)$ belong to the COVID-19 theme, thus occupying a significant percentage of narrative and unconscious space.

\section{Methodological limitations}

Observing the study, both in its development and methodology, it is possible to notice some limitations concerning it.

The sample of subjects involved is not comparable to that of Pesonen and colleagues (2020); in fact, it is reduced to 17. However, it must be considered that the collection is of longer duration, since the researchers requested the narration of some peculiar dreams during the whole Finnish lockdown, not a systematic and 'longitudinal' one that lasted two weeks. Another limiting factor that always concerns the sample is the age of the participants: the group taken into consideration is restricted to young adults, as they were more easily reached through new technologies and social networks, but by making this choice a broader view of the effects of this phenomenon is missing.

Another factor concerns the origin of the clusters. They derive from pre-existing clusters, which come from a Northern European population and were not derived from an exploratory mode.

On the basis of the results obtained it would be interesting to carry out a subsequent study involving a larger representative sample of the Italian population for a subsequent comparison with the results found by Pesonen et $a l$. and for a possible comparison with respect to the two countries.

A further element to be investigated in future research could be the beneficial effect of this type of dream narrative, and thus the ability to lower the level of self-perceived stress. We also believe that this type of study can give support to the need to promote psychotherapeutic interventions aimed at population also as prevention. 


\section{Conclusions}

The COVID-19 pandemic, which has affected the world population, is a traumatic event that has psychological, social and economic repercussions on our daily lives. As already mentioned, many studies have shown substantial changes in the mental health and dream activity of the population and in this study we wanted to explore the dream experience of a non-clinical Italian sample. The qualitative research carried out showed, thanks to the collection of dreams, how effectively the 'unmetabolized' (Ferro, 2002) and traumatic elements of daytime activity found expression in the dream world. The post-traumatic nightmare is a compromise which conceals some aspects of the trauma and which at the same time performs a function of adaptive response to the trauma itself and, as Kohut (1977) pointed out with the self-state dreams, one of the functions of oneiric phenomena consists precisely in the presentation of non-narratable contents, by means of visual contents capable of giving way to a possible thinkability and therefore elaboration. We therefore believe that the massive presence of dream contents concerning the pandemic in the general population should not be underestimated, as can be seen from the limited sample we have presented, since it sheds light on issues which we then find again in the consultation room and which sometimes the patient is unable to express. Further confirmation of the importance of encouraging the narration and collection of dreams was provided by the studies conducted by Nielsen and Levin (2007) according to whom nightmares, although due to a dysfunction of a network of processes, have the adaptive task of cancelling the memory of fearful events: dream activity is characterized by emotional and sense-motor experiences, generated internally and influenced by the experiences of individuals, which promote the reorganization of cortical networks deputed to psychological well-being. Considering all the material that has been collected in our research we were able to observe, in the themes of the transcripts, a withdrawal into oneself by the participants, to be able to think and reflect on their current life, as if it was necessary to lock oneself away to recover energy and inner resources to face the traumatic situation. By promoting dream narration, the experiences lived during the day would find in dreams an 'offline' scenario that allows the development of trauma processing skills and the development of new coping strategies. Bromberg (2006) argued the importance of transforming night dreams into daydreams to give expression and meaning to intrapsychic contents. The dream is therefore a reality to be experienced not only in the room of analysis, but also in the knowledge of the non-clinical population, so we must collect data that implement the metapsychological knowledge (Maggiolini et al., 2012) and transforms it into new psychotherapeutic techniques.

\section{References}

Abdel-Khalek, A. M. (2017). The Association between Reported Nightmares and Depressive Symptoms in a Non-Clinical Large Sample of Arab Students. Sleep Medical Diseases International Journal, 1(2), 00010.

Ajilore, O., Stickgold, R., Rittenhouse, C. D., \& Hobson, J. A. (1995). Nightcap: Laboratory and home-based evaluation of a portable sleep monitor. Psychophysiology, 32(1), 92-98. doi: 10.1111/j.1469-8986.1995.tb03410.

Akkuş, Y., Şahin, S., Kanbay, Y., \& Ünlü, A. A. (2021). Determination of the factors affecting sleep quality in the general population during the early phase of the COVID-19 Pandemic. Journal of Turkish Sleep Medicine, 8(2), 142.

Barrett, D. (2020). Dreams about COVID-19 versus normative dreams: Trends by gender. Dreaming, 30(3), 216-221. doi: 10.1037/drm0000149.

Barrett, D., \& Behbehani, J. (2003). Post-traumatic nightmares in Kuwait following the Iraqi invasion. In Krippner, S. \& Teresa McIntyre, M. (Eds.), Psychological effects of war on civilians: an international perspective (psychological dimensions to war and peace) (pp. 135-144). Amityville, NY: Praeger Publishing.

Belanger, J., \& Kirsten, D. (2006). The Nightmare Encyclopedia (I. Appino, trad.). Milano: Gruppo Editoriale Armenia, 2007.

Bion, W. R. (1992). Cogitation. A cura di Bion F. Londra: Karnak Books.

Bion, W. R. (1994). Clinical seminars and four papers. A cura di Bion F. Londra: Karnak Books. 2008.

Bion, W. R. (1980). Discussions with W. R. Bion. Rome: Curcio Publisher, 1984.

Boldrini, T., Schiano Lomoriello, A., Del Corno, F., Lingiardi, V., \& Salcuni, S. (2020). Psychotherapy during COVID-19: How the clinical practice of Italian psychotherapists changed during the pandemic. Frontiers in psychology, 11, 2716.

Bolognini, S. (a cura di, 2016). Il sogno cento anni dopo. Milano: MIMESIS Edizioni.

Bromberg, P. M. (2006). Awakening the dreamer: Clinical journeys. El Dorado Hills, CA: Analytic Press.

Bulkeley, K., \& Kahan, T. L. (2008). The impact of September 11 on dreaming. Consciousness and Cognition, 17(4), 12481256. doi: 10.1016/j.concog.2008.07.001.

Caccamo, F., Ghedin, S., \& Marogna, C. (2017). Evaluation of burnout and alexithymia in a group of nurses in palliative care: a pilot study. Giornale italiano di medicina del lavoro ed ergonomia, 39(4), 249-255.

Casagrande, M., Favieri, F., Tambelli, R., \& Forte, G. (2020). The enemy who sealed the world: effects quarantine due to the COVID-19 on sleep quality, anxiety, and psychological distress in the Italian population. Sleep medicine, 75, 12-20.

Cullen, W., Gulati, G., \& Kelly, B. D. (2020). Mental health in the COVID-19 pandemic. QJM: An International Journal of Medicine, 113(5), 311-312. doi: 10.1093/qjmed/hcaa110.

Dondi, A., Fetta, A., Lenzi, J., Morigi, F., Candela, E., Rocca, A., Cordelli, D. M., \& Lanari, M. (2021). Sleep disorders reveal distress among children and adolescents during the COVID-19 first wave: results of a large web-based Italian survey. Italian Journal of Pediatrics, 47(1). doi: 10.1186/ s13052-021-01083-8.

Ferro, A. (2002). Fattori di Malattia, fattori di guarigione. Milano: Raffaello Cortina Editore.

Frewen, P. A. (2006). Toward a Psychobiology of Posttraumatic 
Self-Dysregulation: Reexperiencing, Hyperarousal, Dissociation, and Emotional Numbing. Annals of the New York Academy of Sciences, 1071(1), 110-124. doi: 10.1196/annals.1364.010.

Giardino, D. L., Huck-Iriart, C., Riddick, M., \& Garay, A. (2020). The endless quarantine: the impact of the COVID19 outbreak on healthcare workers after three months of mandatory social isolation in Argentina. Sleep medicine, 76, 16-25.

Gorgoni, M., Scarpelli, S., Alfonsi, V., Annarumma, L., Cordone, S., Stravolo, S., \& de Gennaro, L. (2021). Pandemic dreams: quantitative and qualitative features of the oneiric activity during the lockdown due to COVID-19 in Italy. Sleep Medicine, 81, 20-32. doi: 10.1016/j.sleep.2021. 02.006.

Guo, H., \& Shen, H. (2021). Media exposure to COVID-19 epidemic and threatening dream frequency: A moderated mediation model of anxiety and coping efficacy. Dreaming, 31(1), 1-19. doi: 10.1037/drm0000159.

Gupta, M. A. (2020). Spontaneous reporting of onset of disturbing dreams and nightmares related to early life traumatic experiences during the COVID-19 pandemic by patients with posttraumatic stress disorder in remission. Journal of Clinical Sleep Medicine, 16(8), 1419-1420. doi: 10.5664/jcsm. 8562.

Hedrich, R. (2003). Book ReviewThomas Metzinger, Being No One: The Self-Model Theory of Subjectivity. Cambridge, MA: The MIT Press (2003), xiv + 699 pp., Philosophy of Science, 70(3), 634-637. doi: 10.1086/376931.

Herrero San Martin, A., Parra Serrano, J., Diaz Cambriles, T., Arias Arias, E. M., Muñoz Méndez, J., del Yerro ÁLvarez, M. J., \& González Sánchez, M. (2020). Sleep characteristics in health workers exposed to the COVID-19 pandemic. Sleep Medicine, 75, 388-394. doi: 10.1016/j.sleep.2020. 08.013.

Hobson, J. A (2002) Dreaming: an introduction to the science of sleep. (2003). Choice Reviews Online, 40(11), 40-6718. doi: 10.5860/choice.40-6718.

Innocenti, P., Puzella, A., Mogavero, M. P., Bruni, O., \& Ferri, R. (2020). Letter to editor: COVID-19 pandemic and sleep disorders - a web survey in Italy. Neurological Sciences, 41(8), 2021-2022. doi: 10.1007/s10072-020-04523-1.

Kilius, E., Abbas, N. H., McKinnon, L., \& Samson, D. R. (2021). Pandemic Nightmares: COVID-19 Lockdown Associated With Increased Aggression in Female University Students' Dreams. Frontiers in Psychology, 12. doi: 10.3389/ fpsyg.2021.644636.

Kohut, H. (1977). The Restoration of the Self. New York, NY: Int. Univ. Press.

Kramer, M. (2014). An overview of the dreaming process and the selective affective theory of sleep and dreams. Psychotherapie Forum, 19(3-4), 130-137. doi: 10.1007/s00729014-0028-x.

Levin, R., \& Nielsen, T. (2009). Nightmares, bad dreams, and emotion dysregulation. Current Directions in Psychological Science, 18(2), 84-88. doi: 10.1111/j.1467-8721.2009. 01614.

Levin, R., \& Nielsen, T. A. (2007). Disturbed dreaming, posttraumatic stress disorder, and affect distress: A review and neurocognitive model. Psychological Bulletin, 133(3), 482528. doi: 10.1037/0033-2909.133.3.482.

Lin, Y. Q., Lin, Z. X., Wu, Y. X., Wang, L., Zeng, Z. N., Chen, Q. Y., ... \& Wei, S. C. (2021). Reduced sleep duration and sleep efficiency were independently associated with frequent nightmares in chinese frontline medical workers during the coronavirus disease 2019 outbreak. Frontiers in Neuroscience, 14, 1437.

MacKay, C., \& DeCicco, T. L. (2020). Pandemic dreaming: The effect of COVID-19 on dream imagery, a pilot study. Dreaming, 30(3), 222-234. doi: 10.1037/drm0000148.

Maggiolini, A., Lazzaroni, E., \& Crippa, F. (2012). I contenuti tipici dei sogni. Una ricerca su sogni e narrative diurne di adolescenti e giovani adulti [Typical contents of dreams. A research on dreams and waking narratives of adolescents and young adults]. Infanzia e Adolescenza, 11(2), 113-124.

Mellman, T. A., David, D., Bustamante, V., Torres, J., \& Fins, A. (2001). Dreams in the acute aftermath of trauma and their relationship to PTSD. Journal of Traumatic Stress, 14(1), 241-247. doi: 10.1023/a:1007812321136.

Messina, I., Calvo, V., Masaro, C., Ghedin, S., \& Marogna, C. (2021). Interpersonal Emotion Regulation: From Research to Group Therapy. Frontiers in Psychology, 12. doi: 10.3389/fpsyg.2021.636919.

Miller, K. E., Brownlow, J. A., Woodward, S., \& Gehrman, P. R. (2017). Sleep and dreaming in posttraumatic stress disorder. Current psychiatry reports, 19(10), 1-10.

Milstein, G. (2019). Disasters, psychological traumas, and religions: Resiliencies examined. Psychological Trauma: Theory, Research, Practice, and Policy, 11(6), 559-562. doi: $10.1037 / \operatorname{tra} 0000510$.

Mota, N. B., Weissheimer, J., Ribeiro, M., de Paiva, M., AvillaSouza, J., Simabucuru, G., Chaves, M. F., Cecchi, L., Cirne, J., Cecchi, G., Rodrigues, C., Copelli, M., \& Ribeiro, S. (2020). Dreaming during the COVID-19 pandemic: Computational assessment of dream reports reveals mental suffering related to fear of contagion. PLoS One, 15(11), e0242903. doi: 10.1371/journal.pone.0242903.

Musse, F. C. C., Castro, L. D. S., Sousa, K. M. M., Mestre, T. F., Teixeira, C. D. M., Pelloso, S. M., Poyares, D., \& Carvalho, M. D. D. B. (2020). Mental Violence: The COVID19 Nightmare. Frontiers in Psychiatry, 11. doi: 10.3389 /fpsyt.2020.579289.

Nielsen, T. A., \& Zadra, A. (2005). Nightmares and other common dream disturbances. Principles and practice of sleep medicine, 4, 926-935.

Nielsen, T. A., Stenstrom, P., \& Levin, R. (2006). Nightmare frequency as a function of age, gender, and September 11, 2001: Findings from an Internet questionnaire. Dreaming, 16(3), 145-158. doi: 10.1037/1053-0797.16.3.145.

Nielsen, T., \& Levin, R. (2009). Dreams, dreaming theories and correlates of nightmares. In L. R. Squire (Ed.), Encyclopedia of Neuroscience, Vol 3 (pp. 663-669). Oxford: Academic Press.

Nissen-Lie, H. A., \& Stänicke, E. (2014). 'Yes, of course it hurts when buds are breaking': therapist reactions to an adolescent client's sexual material in psychodynamic psychotherapy. Journal of clinical psychology, 70(2), 160-169.

Okada, H., Matsuoka, K., \& Hatakeyama, T. (2005). Individual differences in the range of sensory modalities experienced in dreams. Dreaming, 15(2), 106-115. doi: 10.1037/10530797.15.2.106.

Pesonen, A. K., Lipsanen, J., Halonen, R., Elovainio, M., Sandman, N., Mäkelä, J. M., ... \& Kuula, L. (2020). Pandemic dreams: network analysis of dream content during the COVID-19 lockdown. Frontiers in Psychology, 11, 2569.

Presti, G., Dal Lago, B., Fattori, A., Mioli, G., Moderato, P., 
Sciaretta, L., \& Costantino, M. A. (2020). Mental health support to staff in a major hospital in Milan (Italy) during the COVID-19 pandemic: a framework of actions. General Psychiatry, 33(4).

Revonsuo, A. (2000). The reinterpretation of dreams: An evolutionary hypothesis of the function of dreaming. Behavioral and Brain Sciences, 23(6), 877-901.

Scarpelli, S., Alfonsi, V., Mangiaruga, A., Musetti, A., Quattropani, M. C., Lenzo, V., Freda, et.al. (2021). Pandemic nightmares: Effects on dream activity of the COVID-19 lockdown in Italy. Journal of Sleep Research. [Epub ahead of print]. doi: 10.1111/jsr.13300.

Schredl, M., \& Bulkeley, K. (2020). Dreaming and the COVID19 pandemic: A survey in a U.S. sample. Dreaming, 30(3), 189-198. doi: 10.1037/drm0000146.

Scott, J. C., Harb, G., Brownlow, J. A., Greene, J., Gur, R. C., \& Ross, R. J. (2017). Verbal memory functioning moderates psychotherapy treatment response for PTSD-Related nightmares. Behaviour Research and Therapy, 91, 24-32. doi: 10.1016/j.brat.2017.01.004.

Shatri, H., Putranto, R., Faisal, E., Fitrianti, F., Adhiatma, K., Zulmiyusrini, P., Diba, S. F., \& Lukman, P. R. (2021). Psychotherapy for healthcare provider during COVID-19 pandemic: an evidence based clinical review. Acta Medica Indonesiana, 53(2), 225-232.

Solomonova, E., Picard-Deland, C., Rapoport, I., Pennestri, M., Saad, M., Kendzerska, T., ... Robillard, R. (2021, May 11). Stuck in a lockdown: dreams, bad dreams, nightmares, and their relationship to stress, depression and anxiety during the COVID-19 pandemic. PsyArXiv Preprint, doi: 10.31234/osf.io/hbm84.
Sterpenich, V., Perogamvros, L., Tononi, G., \& Schwartz, S. (2019). Fear in dreams and in wakefulness: Evidence for day/night affective homeostasis. Human Brain Mapping, 41(3), 840-850. doi: 10.1002/hbm.24843.

Stickgold, R. (2005). Sleep-dependent memory consolidation. Nature, 437(7063), 1272-1278. doi: 10.1038/nature04286.

Stickgold, R., Pace-Schott, E., \& Hobson, J. A. (1994). A new paradigm for dream research: mentation reports following spontaneous arousal from REM and NREM sleep recorded in a home setting. Consciousness and Cognition, 3(1), 16-29.

Valli, K., Revonsuo, A., Pälkäs, O., Ismail, K. H., Ali, K. J., \& Punamäki, R. L. (2005). The threat simulation theory of the evolutionary function of dreaming: Evidence from dreams of traumatized children. Consciousness and cognition, 14(1), 188-218.

Van Der Helm, E., \& Walker, M. P. (2012). Sleep and affective brain regulation. Social and Personality Psychology Compass, 6(11), 773-791.

VERBI Software. (2019). MAXQDA 2020 [computer software]. Berlin, Germany: VERBI Software. Avaible from: maxqda.com.

Vindegaard, N., \& Benros, M. E. (2020). COVID-19 pandemic and mental health consequences: Systematic review of the current evidence. Brain, Behavior, and Immunity, 89, 531542. https://doi.org/10.1016/j.bbi.2020.05.048

Zadra, A., \& Donderi, D. C. (2000). Nightmares and bad dreams: their prevalence and relationship to well-being. Journal of abnormal psychology, 109(2), 273.

Zadra, A., Pilon, M., \& Donderi, D. C. (2006). Variety and intensity of emotions in nightmares and bad dreams. The Journal of nervous and mental disease, 194(4), 249-254. 